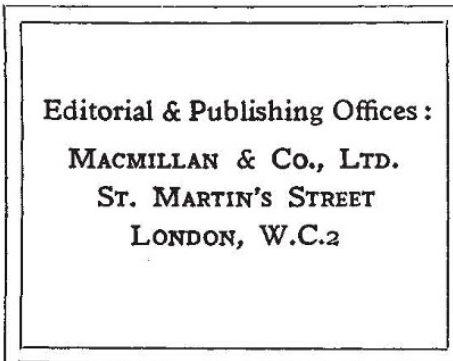

No. 3463

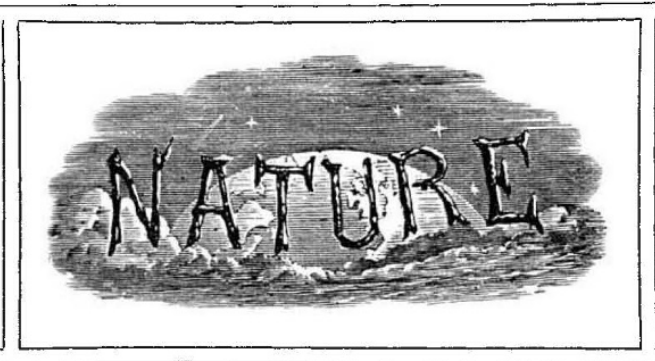

SATURDAY, MARCH I4, I936
Telegraphic Address :

Phusis, Lesquare, LondoN

Telephone Number :

WhitehaLL 8831

\title{
The Civil Service and 'Everyday' Science
}

$\mathrm{D}^{\mathrm{c}}$

URING the Great War, in 1917, a new scheme of examination was adopted for Class I of the Civil Service. This important administrative group of Government services in Great Britain now comprises the Indian and Ceylon Civil, the Foreign Office and Diplomatic, the Consular and Overseas Trade (Intelligence Officer) and Home Civil (Junior Grade of the Administrative Class). The revised scheme provided for examination in two sets of subjects-one compulsory and the other optional. The compulsory set was to include an essay and papers on English, Present Day (contemporary, social, economic and political subjects), Eyeryday Science (general scientific principles and methods), an auxiliary language, and a viva yoce examination. Having passed this qualifying examination, candidates were given a wide choice of subjects, in which advanced knowledge of various branches of science could secure as favourable marks in the competition as classical languages and related literary scholarship. The scheme was generally welcomed because it afforded opportunities for men trained efficiently on varied lines to gain access to the important posts to which these examinations ultimately lead. A specimen paper on general science (for all candidates), appended to the original scheme, asked for just that amount of general scientific knowledge which all public servants might reasonably be expected to possess ; and a wide choice of questions was allowed.

For nineteen years these regulations have been in force, and they have had an encouraging influence on the position of science in secondary-school and university education. They conceded the principle that the rudiments of natural knowledge are an essential part of education for modern life ; and this recognition represented a remarkable advance in the official attitude toward scientific teaching. As to the scope of the "Everyday Science" paper, the existing regulations define it as follows: "Such knowledge will be expected as candidates will have who have studied science intelligently at school and have since kept their eyes open. A liberal choice of questions will be given. Attention should be paid to orderly, effective, and exact expression."

It should be noticed particularly that with the inclusion of "Everyday Science" among the compulsory subjects of the examination, all candidates for the administrative group of the Civil Service were expected to have been taught science while at school, whatever subjects they might specialise in afterwards, and also that they were supposed to maintain interest in scientific matters generally, without practical familiarity with technical details. In other words, all candidates were assumed to have acquired an acquaintance with fundamental scientific principles and methods during their school course, and thus to have been equipped for progressive development in the scientific environment of modern life.

These very admirable intentions have, however, recently been abandoned by the Civil Service Commissioners; and apparently it was not considered necessary to consult scientific authorities before arriving at the decision. In September last the Commissioners announced that, with effect from this year, the subject of "Everyday Science" will be omitted from the compulsory qualifying examination, and that, in its place, some optional questions on science will be included under the subject entitled "Present Day". It appears from 
a question asked by Sir Arnold Wilson in the House of Commons in December last, and a full reply to it communicated by letter to Sir Arnold by Mr. W. S. Morrison, Financial Secretary to the Treasury, that, in taking this step, the Commissioners "obtained the concurrence of the Universities of Oxford and Cambridge, whose considered advice may be taken as representative of general well-informed opinion". What exactly is to be implied by the phrase "Universities of Oxford and Cambridge" we do not know, but if it means that competent scientific authorities were consulted, and that they, after due consideration, deliberately decided that candidates for Civil Service appointments need no longer give evidence that they had "studied science intelligently at school", then we can only conclude that they do not care whether science is taught in school or not. It is difficult to understand how any responsible authority familiar with the science teaching now carried on in our secondary schools could have consented to a decision which must have an adverse effect upon its development.

For several years, there has been a reaction against specialisation of science subjects in schools, and the Board of Education, as well as school examination authorities and the Science Masters' Association, have been engaged in drafting courses of general elementary science. Such schemes are intended to provide suitable scientific education for all, and not intensive study of particular branches of science for pupils who propose to specialise in physics, chemistry or biology for professional reasons. Objections can, of course, be raised to general science courses as being so indefinite and wide in scope that nothing is learned of scientific method, and only confused and incoherent ideas are acquired of the meaning of scientific knowledge. But even if this view be accepted, it does not follow that we must abandon as hopeless the attempts to devise courses of school science suitable for the rank and file and to enable all young people to take intelligent interest in scientific developments in the world around them, whether they leave school at sixteen years or so in age or whether they proceed to a university or other place of higher education.

Among the reasons given by Mr. Morrison for the decision of the Civil Service Commissioners to omit "Everyday Science" from the qualifying examination was that "many candidates at these examinations make this subject in particular one for special cramming, which is one of the most dangerous defects to which the examination system lends itself. In the result, only a very superficial knowledge of the subject was acquired by candidates and a formidable addition was caused to the already severe strain of the examina. tion". The difficulty is a real one, but we suggest that it arises chiefly because of the neglect of the very condition which was intended to be met when "Everyday Science" was made a compulsory subject in the qualifying examination, namely, that candidates would be expected to have "studied science intelligently at school". Many of the candidates have not studied science at all in school, on account of the demands made upon their time by classical languages and literature or other subjects in which they are specialising. The result is that they have to resort to cramming up a subject which ought to have been taught to them while at school, and the experimental character of which is despised by their superior minds.

It may be that, to a certain class of mind, natural phenomena and experimental inquiry make no appeal, and that for pupils of this type the science course should be of a more philosophical kind, or have closer relation to human history. That, however, is not a sufficient reason for omitting all science from the qualifying examination, but only for endeavouring to construct courses which are suitable for sixth form pupils of scholarship standard on the classical side. The inclusion of questions on scientific topics in the "Present Day" paper cannot in any way be accepted as equivalent to the setting of suitable questions to test whether or no a candidate has followed a natural science course while at school and has maintained an interest in what he has learnt.

Whatever opinion may be held as to the value of instruction in natural science of any kind while at school, the result of the decision of the Civil Service Commissioners is that specialists in classical or modern languages, in history and other literary subjects, are no longer encouraged to study science at any time in their educational careers, and that they may enter the Civil Service without even the knowledge required to pass in elementary general science in a School Certificate examination. To us this seems deplorable, and if the scientific societies in Great Britain could speak with a united voice, as the Federation of British Industries does for organised industry, such a disastrous blow to science teaching in schools and the scientific comprehension of our future administrators would never be tolerated. 